\title{
Seeking safe jobs in unsure times
}

\section{What qualities will employers be looking for in a "buyer's market" for labour, asks Richard Pearson*?}

WITH the new academic year now in full swing, the shrinking job market is worrying many final year students as well as those competing to enter higher education and pondering their choice of subject. The current ethos is that vocational subjects offer the best employment prospects. How then have science graduates fared so far in the 1980s and how can students and careers advisers assess which jobs and careers are likely to be in demand five or more years ahead? The "cycle of mismatch" caused by the short-term leads and lags attending market signals is the obvious problem (see Nature, 308, 83; 1983). The chief need when assessing job prospects is to understand the changing pattern of employers' demands and the critical features, economic, social and technical, likely to bring about future change. Indeed the only sure thing about a detailed long-term manpower forecast is that it will be wrong.

The United Kingdom is unique in having up-to-date information about the transition from higher education into employment. Since the 1960 s, data have been collected from graduates about their "first destinations" six months after graduation. The published data provide us with a valuable time-perspective on changing graduate employment and on the jobs found by graduates in different subject groups.

What, then, were the employment experiences of those graduating in science in the early 1980 s, and how have they been affected by the general rise in unemployment? Statistics can of course hide as much as they reveal and, while the precise levels of under-employment or of unemployment may be debated, the statistics do reveal the main trends. Graduate unemployment has grown sharply over the past five years (Fig. 1), and one in six of those graduating in 1982 were unemployed six months later. Science subjects have fared worse than the average over the years, while engineering and the professional disciplines such as medicine have fared best.

The differences between science subjects were, however, even greater, with 19.2 per cent of biologists being unemployed in 1982 , worse than in chemistry (14.3 per cent) and a rate more than twice that for mathematics and computing science $(9.3$ per cent). By contrast, unemployment in

*Institute of Manpower Services, University of Sussex, Falmer, Brighton BNI 9RF, UK. electrical/electronic engineering was down at 7 per cent (Table 1). Women in the sciences had a 12 per cent unemployment rate while the figure for their male counterparts was considerably higher at around 17 per cent.

Although unemployment was rising rapidly, the majority of science graduates still entered some form of employment (43 per cent) or further training (33 per cent), with most of those in employment working in industry. However, in terms of job content, only just over one in ten went into scientific or related work.

Table 1 Unemployment six months after graduation

\section{Biology}

Chemistry

Maths/computer science

All science

Electrical engineering

All engineering

All graduates

$19.2 \%$

$14.3 \%$

$9.3 \%$

$16.5 \%$

$7.0 \%$

$11.0 \%$

$13.5 \%$

Figures are for 1982. Source: Universities Statistical Record.

The majority of graduates have, therefore, gone into non-vocational jobs. What, then, has been the nature of these jobs and what qualities have recruiters been seeking? While job seekers usually expect jobs in multinational companies to be different from those in, say, a local food processing company, many do not realize that there are as many differences in jobs and careers within organizations as between them. There is no such thing as a "graduate" job. Employers seek to fill a diversity of jobs for many different past.

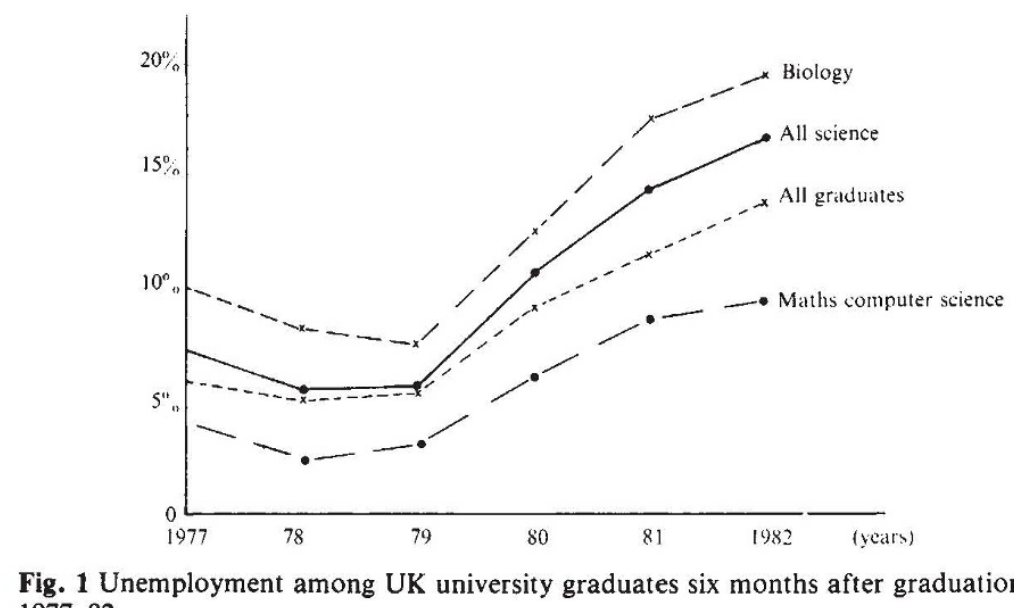

Fig. 1 Unemployment among UK university graduates six months after graduation for the years 1977-82.

reasons.

Thus graduates may be sought for their scientific knowledge, or because they have a "trained" mind. Some are sought as high-fliers, others to fill short-term vacancies with prospects only to junior management.

Some recruits are expected to be productive straight away, others are carefully groomed for senior management. Different jobs need different types of people, a fact not always recognized by the recruiters themselves. It is a foolish employer who seeks to find the "best" graduates available when the jobs available of fer only limited scope and career potential. It is only for the specialist functions, which account for perhaps one third of the vacancies, that degree subject is critical, and in the scientific area a postgraduate qualification is often a necessary entry requirement. For most jobs, including many of those in science, it is the personal qualities that are important.

Looking ahead to the late $1980 \mathrm{~s}$, the chief determinant of job prospects is obviously going to be the state of the economy. For the potential job seeker, it will be important to remember that strictly vocational jobs will continue still to be in a minority, and that only in certain areas, probably related to information technology, is it likely that all those qualifying in technical subjects will be able to move into related specialist jobs. The prime need will be for flexibility about type of job, employer, and subsequent use of subject. Most importantly, personal qualities - motivation, communication skills and especially numeracy - will continue to be as critical in the future as in the

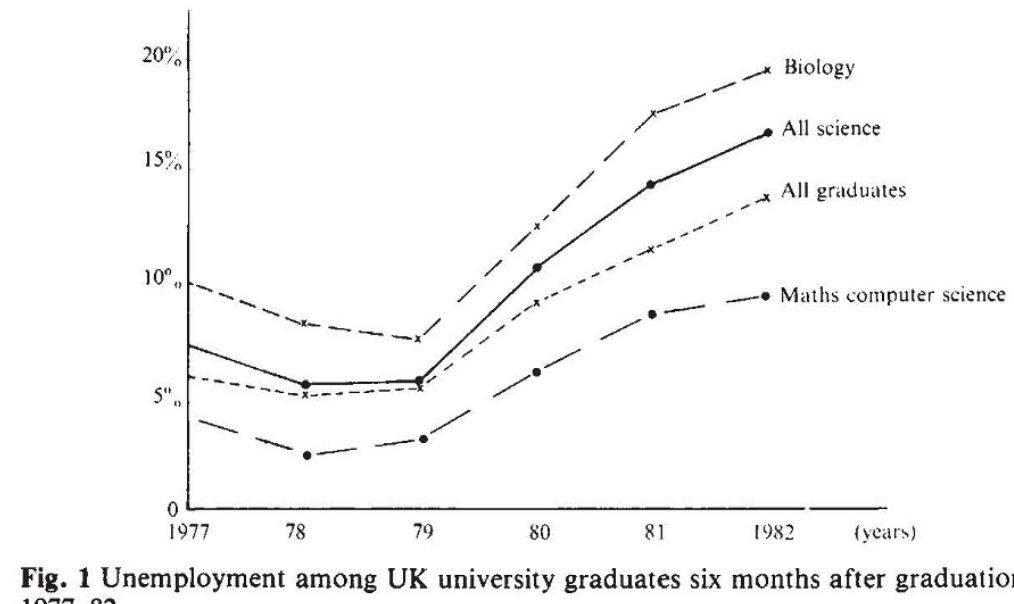

